Article

\title{
Chemical Oxidative Polymerization of 2-Aminothiazole in Aqueous Solution: Synthesis, Characterization and Kinetics Study
}

\author{
Hua Zou ${ }^{1}$, Lu Wang ${ }^{1}$, Xia Wang ${ }^{1, *}$, Pengfei Lv ${ }^{1}$ and Yaozu Liao ${ }^{2, *}$ \\ 1 School of Materials Science and Engineering, University of Shanghai for Science and Technology, \\ Shanghai 200093, China; hua.zou@usst.edu.cn (H.Z.); wanglu1390636@163.com (L.W.); \\ feiniao416@163.com (P.L.) \\ 2 State Key Laboratory for Modification of Chemical Fibers and Polymer Materials, \\ College of Materials Science and Engineering, Donghua University, Shanghai 201620, China \\ * Correspondence: wangxia@usst.edu.cn (X.W.); yzliao@dhu.edu.cn (Y.L.) \\ Academic Editor: Graeme Moad \\ Received: 8 September 2016; Accepted: 16 November 2016; Published: 23 November 2016
}

\begin{abstract}
The chemical oxidative polymerization of 2-aminothiazole (AT) was studied in aqueous solution using copper chloride $\left(\mathrm{CuCl}_{2}\right)$ as an oxidant. The effect of varying the reaction temperature, reaction time and oxidant/monomer molar ratio on the polymer yield was investigated. The resulting poly(2-aminothiazole)s (PATs) were characterized by FTIR, ${ }^{1} \mathrm{H}$ NMR, UV-vis, gel permeation chromatography, scanning electron microscopy, thermogravimetric analysis and four-point probe electrical conductivity measurements. Compared with a previous study, PATs with higher yield $(81 \%)$ and better thermal stability could be synthesized. The chemical oxidative polymerization kinetics of AT were studied for the first time. The orders of the polymerization reaction with respect to monomer concentration and oxidant concentration were found to be 1.14 and 0.97 , respectively, and the apparent activation energy of the polymerization reaction was determined to be $21.57 \mathrm{~kJ} / \mathrm{mol}$.
\end{abstract}

Keywords: poly(2-aminothiazole); chemical oxidative polymerization; yield; thermal stability; kinetics

\section{Introduction}

Conducting polymers have attracted considerable attention for several decades, among which the most widely studied examples are the heterocyclic polymers, such as polyaniline, polypyrrole and polythiophene [1]. 2-Aminothiazole (AT) is a heterocyclic amine combining the chemical structures of aniline, pyrrole and thiophene. Owing to the existence of sulfur- and nitrogen-rich subgroups, AT and its derivatives demonstrated excellent adsorption properties to heavy metal ions [2-8]. For example, AT-modified silica gels were able to adsorb and preconcentrate $\mathrm{Ni}(\mathrm{II}), \mathrm{Cu}(\mathrm{II}), \mathrm{Cd}(\mathrm{II}), \mathrm{Zn}(\mathrm{II})$ and $\mathrm{Pb}$ (II) [7]; also, AT-functionalized polyacrylonitrile and polystyrene exhibited an excellent selectivity for adsorption of $\mathrm{Hg}(\mathrm{II})$ and $\mathrm{Au}(\mathrm{III})$ ions in aqueous solution [8]. Due to the high sulfur and nitrogen atom molar ratio (30\%) in AT molecules, which is much higher than that in aniline $(7 \%)$ and pyrrole $(10 \%)$, it is expected that the adsorption capacity of AT would be considerably enhanced after polymerization [9].

Similar to other heterocyclic conducting polymers, both electrochemical and chemical oxidative syntheses of poly(2-aminothiazole) (PAT) have been studied. Considerable effort has been devoted to electrochemical polymerization of AT [10-15]. However, there are only a few studies on synthesis of PAT by chemical oxidative polymerization, which has an obvious advantage in production of polymers on a large scale. The chemical oxidative polymerization of AT has been conducted using different oxidant/solvent systems, including sodium hypochloride/acetic acid aqueous solution [16,17], $\mathrm{CuCl}_{2} \cdot 6 \mathrm{H}_{2} \mathrm{O} / 1$,4-dioxane [18], benzoyl peroxide/1,4-dioxane [19], and anhydrous $\mathrm{FeCl}_{3} /$ nitromethane $\left(\mathrm{CH}_{3} \mathrm{NO}_{2}\right)$ at a low oxidant/monomer molar ratio (as low as 0.01) [20]. 
In a recent work [21], we described the preparation of PAT by chemical oxidative polymerization using a low amount of copper chloride $\left(\mathrm{CuCl}_{2} \cdot 2 \mathrm{H}_{2} \mathrm{O}\right)$ as an oxidant in aqueous solution (see Scheme 1), which is known as a cheap, non-toxic, and environment-friendly solvent. It is noteworthy that the polymerization was conducted without any acid being added. However, that paper focused on the adsorption properties of PAT for $\mathrm{Hg}$ (II) in aqueous solution. In the present work, a systematic investigation of the chemical oxidative polymerization of AT in aqueous solution is reported. The optimal conditions for synthesis were determined by examination of the effect of varying reaction temperature, reaction time, and oxidant/monomer molar ratio on the yield of PAT. The structure, morphology, thermal stability and conductivity of the polymers were investigated. On the other hand, the kinetics of chemical polymerization of pyrrole and aniline have been well studied with a wide range of experimental techniques in the literature [22-28]. However, as far as we are aware, no study has been undertaken on the kinetics of the chemical polymerization of AT. In this paper, the chemical oxidative polymerization kinetics of AT were studied for the first time. This work lays the foundation for our ongoing research on the preparation of colloidal dispersions of PAT.

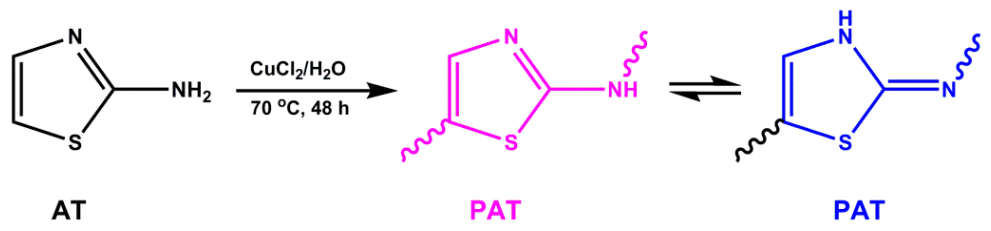

Scheme 1. Synthetic route to poly(2-aminothiazole) PAT with two tautomeric forms.

\section{Materials and Methods}

\subsection{Materials}

AT $\left(97 \%\right.$, Sigma-Aldrich, St. Louis, MO, USA) and $\mathrm{CuCl}_{2} \cdot 2 \mathrm{H}_{2} \mathrm{O}(99 \%$, Sinopharm Chemical Reagent, Shanghai, China) were used as received. All water used in these experiments was deionized $(>18 \mathrm{M} \Omega$ ) using a Milli-Q water purification system (Millipore Corporation, Billerica, MA, USA).

\subsection{Synthesis of PAT}

A typical synthesis of PAT was conducted as follows: $4.0 \mathrm{~g}(40 \mathrm{mmol})$ of AT monomer and $100 \mathrm{~mL}$ of $\mathrm{H}_{2} \mathrm{O}$ were charged into a $250 \mathrm{~mL}$ three-neck flask equipped with a magnetic stirrer, a thermometer, a Graham condenser and a heating mantle. The solution was then stirred and heated to $70{ }^{\circ} \mathrm{C}$, followed by dropwise addition of $20 \mathrm{~mL}$ of aqueous solution containing $1.38 \mathrm{~g}(8 \mathrm{mmol}$, oxidant/monomer molar ratio of 0.2 ) of $\mathrm{CuCl}_{2} \cdot 2 \mathrm{H}_{2} \mathrm{O}$. The color of the solution changed from pale yellow to brown-black once the oxidant solution was added. The reaction was allowed to proceed for various reaction times. After the reaction, the polymer was washed thoroughly three times with deionized water. All the products were dried in a vacuum oven to constant weight. Polymer yields of the polymerization reaction were calculated based on the method normally used for chemical synthetic conducting polymers by dividing the mass of the original PAT by that of the AT used.

\subsection{Kinetics Studies}

The kinetics of the polymerization were studied by monitoring the PAT concentration in the early stage of the polymerization using a parallel reactor [29]. A series of experiments were conducted at $70{ }^{\circ} \mathrm{C}$ at different time intervals $(10-110 \mathrm{~min})$ to establish the dependence of the initial polymerization rate $\left(R_{\mathrm{i}}\right)$ of $\mathrm{AT}$ on monomer concentration (AT) and oxidant concentration $\left(\mathrm{CuCl}_{2}\right)$. The polymerization reaction order with respect to monomer concentration was determined by conducting the polymerization reaction at different monomer concentrations (AT) $(0.1-0.4 \mathrm{~mol} / \mathrm{L})$ and a fixed oxidant concentration of $4 \mathrm{mmol} / \mathrm{L}$. The polymerization reaction order with respect to oxidant concentration was determined by conducting the polymerization reaction at different 
oxidant concentrations $\left(\mathrm{CuCl}_{2}\right)(0.1-0.4 \mathrm{~mol} / \mathrm{L})$ and a fixed monomer concentration of $0.4 \mathrm{~mol} / \mathrm{L}$. The thermodynamic parameters were determined by conducting the polymerizations at $50,60,70$ and $80^{\circ} \mathrm{C}$ at a fixed monomer concentration $(0.4 \mathrm{~mol} / \mathrm{L})$ and a fixed oxidant concentration $(0.4 \mathrm{~mol} / \mathrm{L})$ at different time intervals (10-110 $\mathrm{min})$.

\subsection{Characterization}

FTIR spectra were recorded on a PerkinElmer Spectrum 100 FTIR spectrometer (PerkinElmer, Waltham, MA, USA) in KBr. ${ }^{1} \mathrm{H}$ NMR spectra were taken using a BrukerAvance 400 spectrometer (Bruker, Billerica, MA, USA). UV-vis absorption spectra were recorded using a Lambda $750 \mathrm{UV}$-vis spectrophotometer (PerkinElmer, Waltham, MA, USA) in dimethyl sulfoxide solution. Molecular weight data were obtained by gel permeation chromatograms (GPC, Agilent Technologies, Santa Clara, CA, USA) with an Agilent 1100 system using dimethylformamide as an eluent. The morphology and diameter of the polymer particles were evidenced by scanning electron microscopy (SEM, FEI, Amsterdam, The Netherlands) on a Quanta FEG 450 microscope. Samples were dried and gold-coated prior to examination. Thermogravimetric analysis (TGA) was carried out with a PerkinElmer Pyris 1 TGA apparatus (PerkinElmer, Waltham, MA, USA) in $\mathrm{N}_{2}$ at a heating rate of $10^{\circ} \mathrm{C} / \mathrm{min}$ from room temperature to $600{ }^{\circ} \mathrm{C}$. Electrical conductivities were measured under ambient condition using a standard four-probe method on compressed pellets with a probe station CascadeM150 connected to the Keithley 4200 semiconductor analyzer (Keithley Instruments Inc., Cleveland, OH, USA).

\section{Results and Discussion}

\subsection{Optimization of the Polymerization Conditions}

The effects of reaction temperature, time and oxidant/monomer molar ratio on the yield of PAT were studied to optimize the synthesis. Figure 1 presents the effect of polymerization temperature and time on the polymer yields at a fixed oxidant/monomer molar ratio of 0.2 . The polymer yield increased substantially with increasing polymerization temperature. Meanwhile, the polymer yield increased with increasing polymerization time from $1 \mathrm{~h}$ to approximately $40 \mathrm{~h}$. However, with further increase of the polymerization time to $56 \mathrm{~h}$, the polymer yield increased slightly. Therefore, $70{ }^{\circ} \mathrm{C}$ and $48 \mathrm{~h}$ were selected as the optimal polymerization temperature and time, respectively. This also suggests that the polymerization probably proceeds via a step-by-step mechanism.

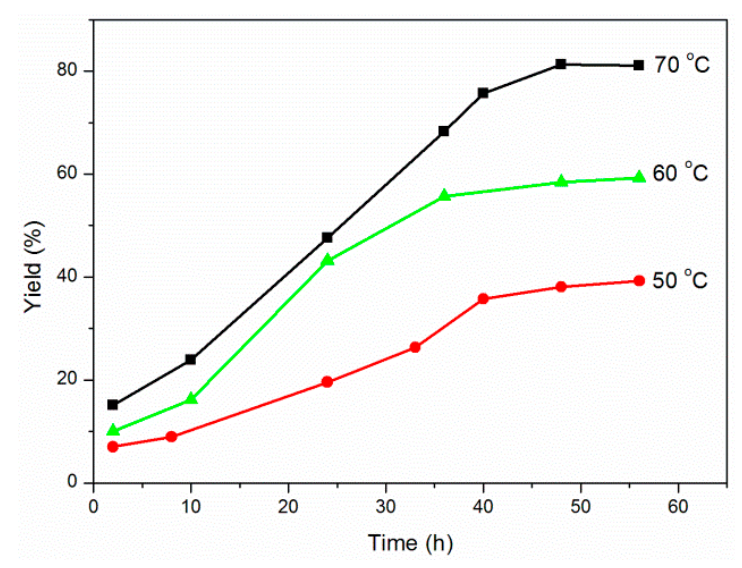

Figure 1. Effects of polymerization temperature and time on the yield of PAT at synthesized at a fixed oxidant/monomer molar ratio of 0.2 .

Figure 2 shows the effects of oxidant/monomer molar ratio and polymerization time on the yield of PAT synthesized at $70{ }^{\circ} \mathrm{C}$. As expected, the polymer yield was improved with increasing oxidant/monomer molar ratio. This is reasonable because a higher oxidant/monomer molar ratio 
can generate more radical species, which can accelerate the polymerization reaction and improve the polymer yield. A very high yield of PAT $(\sim 81 \%)$ was obtained when the polymerization time was $48 \mathrm{~h}$ and the oxidant/monomer molar ratio was 0.2 , whereas the yield was $78 \%$ with $\mathrm{FeCl}_{3}$ as an oxidant in nitromethane under the same conditions [20].

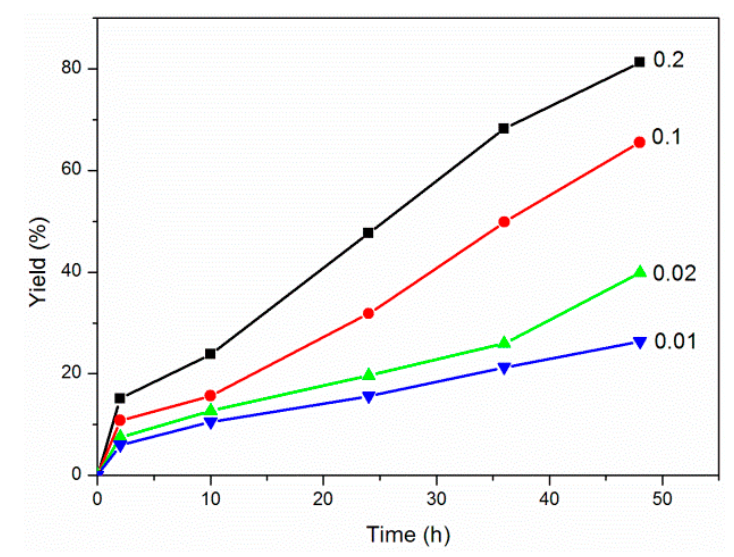

Figure 2. Effects of oxidant/monomer molar ratio and polymerization time on the yield of PAT synthesized at $70{ }^{\circ} \mathrm{C}$.

\subsection{Structure and Morphology}

The chemical structure of PAT was characterized with FTIR and ${ }^{1} \mathrm{H}$ NMR spectroscopies (see Figures S1 and S2, respectively). The results are similar to our previous studies [20,21], suggesting that the polymerization was initiated by the oxidation of $-\mathrm{NH}_{2}$.

Figure 3 shows the UV-vis spectra of AT and PATs synthesized with different oxidant/solvent systems but under identical other conditions $\left(70^{\circ} \mathrm{C}, 48 \mathrm{~h}\right.$ and oxidant/monomer molar ratio of 0.2$)$. The spectrum of AT showed a peak at $267 \mathrm{~nm}$ belonging to the $\pi \rightarrow \pi^{*}$ transition of the thiazole ring. Compared with that of the AT monomer, it is obvious that the spectra of the PATs are considerably red shifted, which is a clear evidence of the formation of conjugation after polymerization [20]. The spectrum of PAT synthesized with $\mathrm{CuCl}_{2} / \mathrm{H}_{2} \mathrm{O}$ not only has a peak at $\sim 267 \mathrm{~nm}$, but also has a broad absorption band at around $450 \mathrm{~nm}$ with a long tail extending to $750-800 \mathrm{~nm}$, which could be attributed to the $\pi \rightarrow \pi^{*}$ transition of the conjugated polymer. The onset wavelengths were red shifted with decreasing oxidant/monomer molar ratio from 0.2 to 0.01 (see Figure S3), probably due to the enhanced conjugation length and molecular weight.

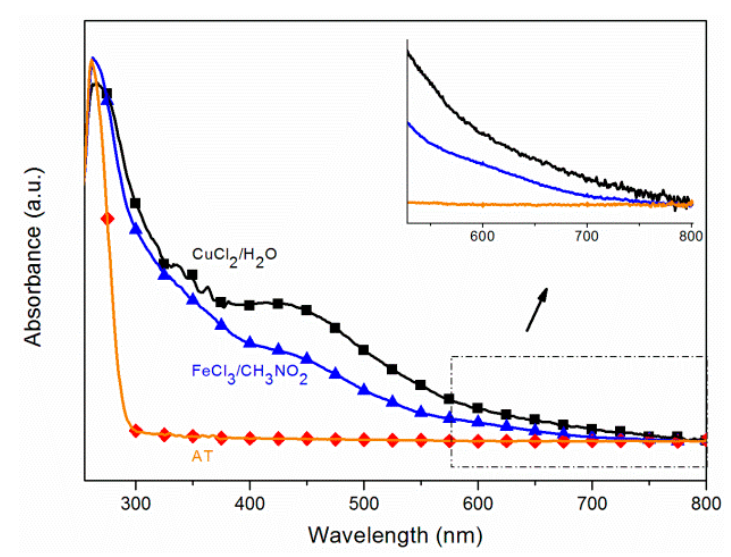

Figure 3. UV-vis spectra of 2-aminothiazole (AT) and PATs synthesized with different oxidant/solvent systems at the same conditions $\left(70{ }^{\circ} \mathrm{C}, 48 \mathrm{~h}\right.$ and oxidant/monomer molar ratio of 0.2$)$. 
Compared with that synthesized with $\mathrm{FeCl}_{3} / \mathrm{CH}_{3} \mathrm{NO}_{2}$, the spectrum of PAT synthesized with $\mathrm{CuCl}_{2} / \mathrm{H}_{2} \mathrm{O}$ shows a weaker absorption band and a shorter tail, indicating the PAT probably has a longer conjugation length and higher molecular weight. To confirm this possible correlation, the molecular weight of PAT was determined by GPC. The number-average molecular weight $\left(M_{n}\right)$ and weight-average molecular weight $\left(M_{\mathrm{W}}\right)$ were $5.90 \times 10^{3}$ and $8.12 \times 10^{3}$, respectively, higher than those synthesized with $\mathrm{FeCl}_{3} / \mathrm{CH}_{3} \mathrm{NO}_{2}$ under the same conditions $\left(M_{\mathrm{n}}=4.48 \times 10^{3}\right.$ and $M_{\mathrm{W}}=7.32 \times 10^{3}$ ) [20], respectively. This can be explained by the fact that $\mathrm{CuCl}_{2}$ is a milder oxidant than $\mathrm{FeCl}_{3}$, resulting in a lower rate of polymerization and higher molecular weights.

The morphology of the PAT powder was examined by SEM. As shown in Figure 4, the particles had a granular morphology with an average size of approximately $400 \mathrm{~nm}$. This is the most common morphology observed for conducting polymers, as the typical conditions used for the preparation of conducting polymer by chemical oxidative polymerization involve a high concentration of nucleates that are produced during short induction period [30]. Due to the limited solubility of nucleates in water, they separate from aqueous medium. The random aggregation of nucleates followed by polymer-chain growth thus gives rise to the globular morphology [31]. This concept of morphology formation was proposed for polyaniline but it also seems to be applicable also to related polymers such as polypyrrole and PAT. For example, similar morphology was observed for polypyrrole nanoparticles prepared by oxidative $\mathrm{H}_{2} \mathrm{O}_{2}$ initiated polymerization [32]. It should also be mentioned that the mean size of the granules was much larger than that prepared with $\mathrm{FeCl}_{3} / \mathrm{CH}_{3} \mathrm{NO}_{2}$, indicating that the morphology of the PAT was substantially affected by the oxidant/solvent system.

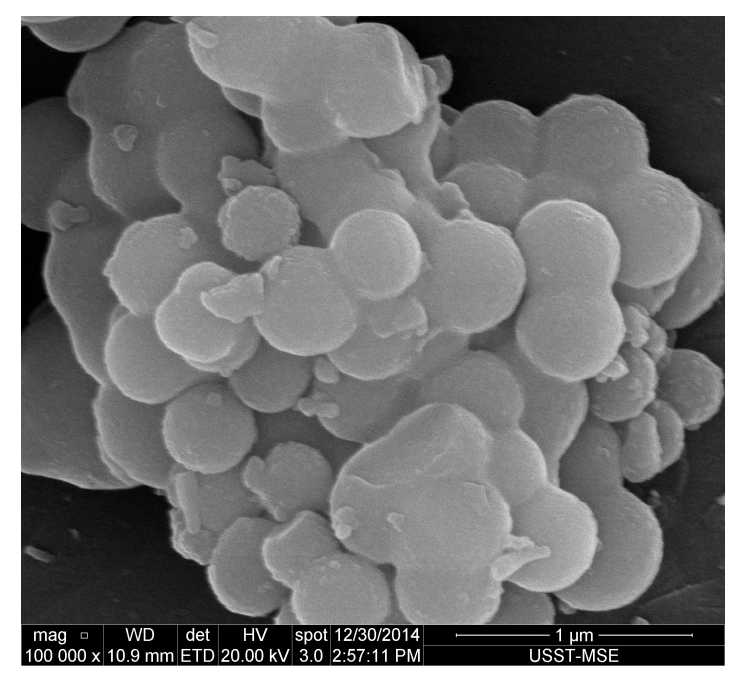

Figure 4. A representative SEM image depicting the granular morphology of PAT powder (prepared at $70^{\circ} \mathrm{C}, 48 \mathrm{~h}$ and oxidant/monomer molar ratio of 0.2 ).

\subsection{Thermal Stability}

The TGA curves of PATs synthesized at various oxidant/monomer molar ratios are presented in Figure 5. It is shown that the thermal stability of PATs increased with decreasing oxidant/ monomer molar ratio, indicating that PATs with longer conjugation length and higher molecular weight were formed at a lower oxidant/monomer molar ratio. This is supported by our GPC results, which showed that the $M_{\mathrm{n}}$ values were $5.9 \times 10^{3}, 26.9 \times 10^{3}$ and $199 \times 10^{3}$, at the oxidant/monomer molar ratios of $0.2,0.1$, and 0.02 , respectively. For oxidant/monomer molar ratio of 0.01 , the GPC data could not be obtained due to the poor solubility of the resulting polymer.

We further compared the initial decomposition temperature of PATs prepared in this work and those prepared with $\mathrm{FeCl}_{3} / \mathrm{CH}_{3} \mathrm{NO}_{2}$ in our previous study [20]. The results are shown in Table 1 . Obviously, PATs prepared with $\mathrm{CuCl}_{2} / \mathrm{H}_{2} \mathrm{O}$ showed much better thermal stability than those prepared 
with $\mathrm{FeCl}_{3} / \mathrm{CH}_{3} \mathrm{NO}_{2}$. This could also be ascribed to their longer conjugation length and higher molecular weight, which is in good agreement with our UV-vis and GPC study.

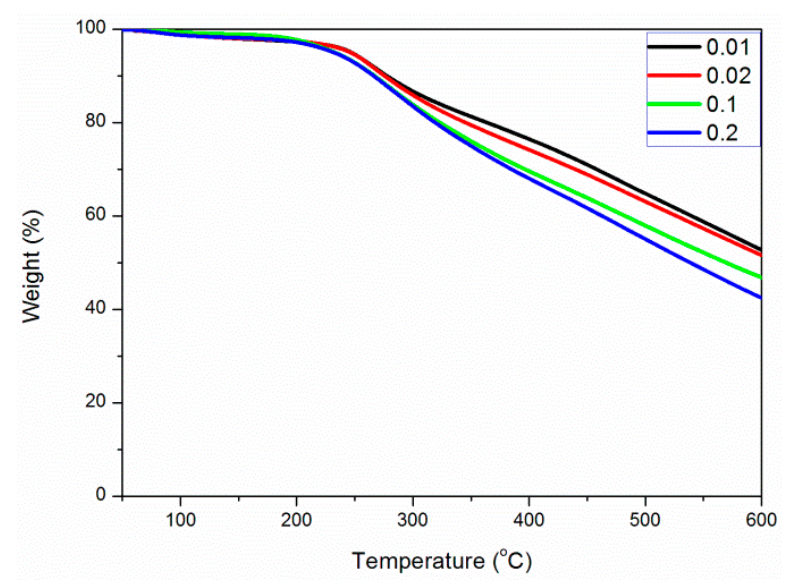

Figure 5. TGA curves of PATs synthesized at various oxidant/monomer molar ratios $\left(70{ }^{\circ} \mathrm{C}, 48 \mathrm{~h}\right)$.

Table 1. Comparison of the initial decomposition temperature of PATs prepared with $\mathrm{CuCl}_{2} / \mathrm{H}_{2} \mathrm{O}$ and $\mathrm{FeCl}_{3} / \mathrm{CH}_{3} \mathrm{NO}_{2}\left(70{ }^{\circ} \mathrm{C}, 48 \mathrm{~h}\right)$.

\begin{tabular}{ccc}
\hline Oxidant/Monomer molar ratio & $\mathrm{CuCl}_{2} / \mathrm{H}_{\mathbf{2}} \mathbf{O}\left({ }^{\circ} \mathrm{C}\right)$ & $\mathrm{FeCl}_{3} / \mathrm{CH}_{3} \mathbf{N O}_{\mathbf{2}}\left({ }^{\circ} \mathrm{C}\right)[20]$ \\
\hline 0.2 & 220 & 135 \\
0.1 & 224 & 165 \\
0.02 & 236 & 183 \\
0.01 & 240 & 210 \\
\hline
\end{tabular}

\subsection{Electrical Conductivity}

Table 2 shows the electrical conductivities of PATs before and after doping with $\mathrm{I}_{2}$. The original PATs showed poor conductive properties $\left(\leq 1.0 \times 10^{-13} \mathrm{~S} / \mathrm{cm}\right)$. These conductivity values were in very good agreement with previous studies $[16,20]$. However, the electrical conductivities of PATs could be improved by around 9 orders of magnitude up to $2.1 \times 10^{-4} \mathrm{~S} / \mathrm{cm}$ upon $\mathrm{I}_{2}$ doping for $24 \mathrm{~h}$.

Table 2. Effect of oxidant/monomer molar ratio and doping time on electrical conductivity of PAT $\left(70{ }^{\circ} \mathrm{C}, 48 \mathrm{~h}\right)$.

\begin{tabular}{cccc}
\hline Oxidant/Monomer molar ratio & Original $\mathbf{( S / c m )}$ & $\mathbf{1 2} \mathbf{h ~} \mathbf{( S / c m )}$ & $\mathbf{2 4} \mathbf{~ h ~} \mathbf{( S / c m )}$ \\
\hline 0.2 & $1.0 \times 10^{-14}$ & $1.0 \times 10^{-7}$ & $1.3 \times 10^{-5}$ \\
0.1 & $5.0 \times 10^{-14}$ & $3.6 \times 10^{-7}$ & $3.9 \times 10^{-5}$ \\
0.02 & $3.0 \times 10^{-14}$ & $9.0 \times 10^{-7}$ & $1.7 \times 10^{-4}$ \\
0.01 & $1.0 \times 10^{-13}$ & $4.0 \times 10^{-6}$ & $2.1 \times 10^{-4}$ \\
\hline
\end{tabular}

\subsection{Kinetics of Polymerization}

We examined how the rate of polymerization of AT was affected by the monomer concentration, the oxidant concentration and the temperature in the early stages of the polymerization.

\subsubsection{Effect of Monomer Concentration}

Chemical oxidative polymerization of AT was carried out at $70{ }^{\circ} \mathrm{C}$ at different monomer concentrations (AT) (0.1-0.4 M) at different time intervals (10-110 min). As shown in Figure 6a, polymer concentration (PAT) was found to vary linearly with time. The initial polymerization rate 
$\left(R_{\mathrm{i}}\right)$ at corresponding monomer concentration could be obtained from the slope according to the following equation:

$$
R_{\mathrm{i}}=\frac{W_{\mathrm{PAT}}}{V \times M_{\mathrm{AT}} \times t}=\frac{[\mathrm{PAT}]}{M_{\mathrm{AT}} \times t}
$$

where $W_{\text {PAT }}$ is the weight of obtained polymer, $V$ is the volume of the reaction mixture in litre, $M_{\mathrm{AT}}$ is the molecular weight of the monomer, and $t$ is the time.

a

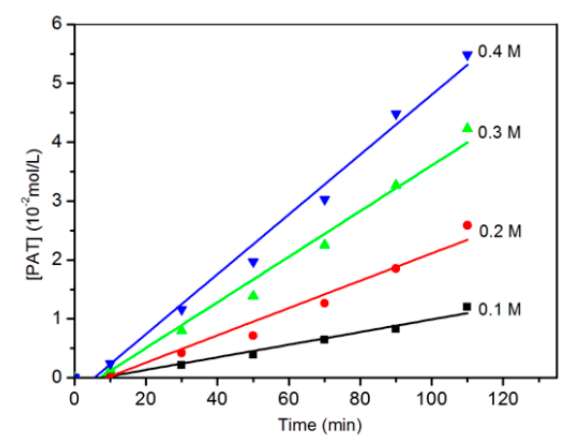

b

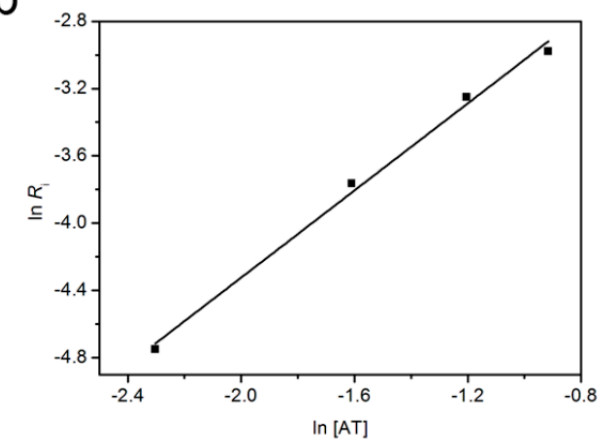

Figure 6. (a) Effect of monomer concentration on the concentration of PAT at different time intervals; (b) plot of $\ln R_{\mathrm{i}}$ versus $\ln [\mathrm{AT}]$.

Based on the $R_{\mathrm{i}}$ values at different monomer concentrations (AT) obtained from Figure 6a, the relationship between $\ln R_{\mathrm{i}}$ and $\ln (\mathrm{AT})$ was established, see Figure $6 \mathrm{~b}$. The slope of this linear relationship was found to be $1.14 \pm 0.03$, indicating that the order of the polymerization reaction with respect to the monomer concentration was $1.14 \pm 0.03$. Thus the initial rate of the polymerization reaction increases with increasing monomer concentration.

\subsubsection{Effect of the Oxidant Concentration}

Similarly, the chemical oxidative polymerization of AT was carried out at $70{ }^{\circ} \mathrm{C}$ at different oxidant concentrations $\left(\mathrm{CuCl}_{2}\right)(0.1-0.4 \mathrm{~mol} / \mathrm{L})$ at different time intervals $(10-110 \mathrm{~min})$. As shown in Figure $7 \mathrm{a}$, the plot of polymer concentration (PAT) versus $t$ at each $\left(\mathrm{CuCl}_{2}\right)$ was also found to be linear, and each initial polymerization rate $\left(R_{\mathrm{i}}\right)$ was obtained from the slope of the line. Then the relationship between $\ln R_{\mathrm{i}}$ and $\ln \left(\mathrm{CuCl}_{2}\right)$ was established, see Figure $7 \mathrm{~b}$. The slope of this linear relationship was found to be $0.97 \pm 0.05$, indicating that the order of the polymerization reaction with respect to the oxidant concentration was $0.97 \pm 0.05$. Thus the initial rate of polymerization reaction increases with increasing oxidant concentration.

a

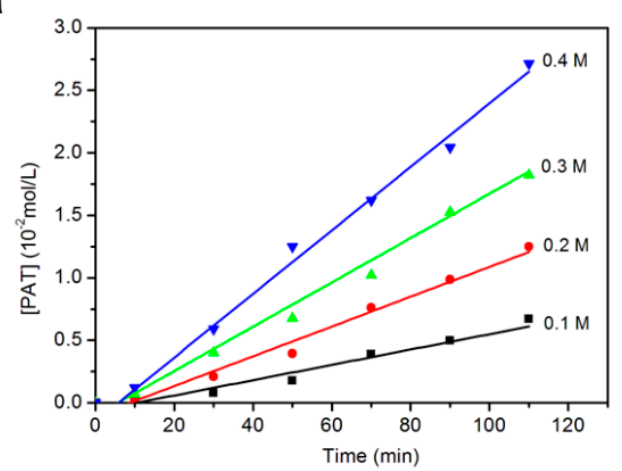

b

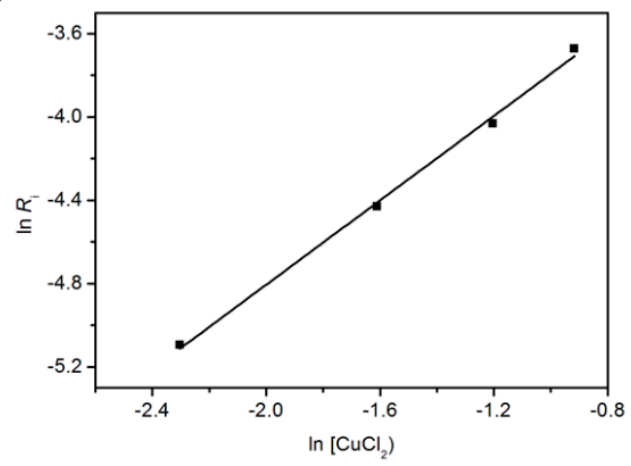

Figure 7. (a) Effect of oxidant concentration on the concentration of PAT at different time intervals; (b) the plot of $\ln R_{\mathrm{i}}$ versus $\ln \left(\mathrm{CuCl}_{2}\right)$. 


\subsubsection{Calculation of the Thermodynamic Parameters}

To study the effect of polymerization temperature, chemical oxidative polymerizations of AT were further carried out at $50,60,70$, and $80^{\circ} \mathrm{C}$ at a fixed monomer concentration $(0.4 \mathrm{~mol} / \mathrm{L})$ and a fixed oxidant concentration $(0.4 \mathrm{~mol} / \mathrm{L})$ at different time intervals (10-110 $\mathrm{min})$. The [PAT]-time curves were shown in Figure 8a, and $R_{\mathrm{i}}$ values at different temperatures were obtained from the slope of the lines. Meanwhile, $R_{\mathrm{i}}$ could be expressed by the following reaction rate equation:

$$
R_{\mathrm{i}}=k(\mathrm{AT})^{1.14}\left(\mathrm{CuCl}_{2}\right)^{0.97}
$$

where $k$ is the reaction rate constant. According to this equation, the values of $k$ at $50,60,70$ and $80^{\circ} \mathrm{C}$ were calculated to be $1.07 \times 10^{-3}, 1.40 \times 10^{-3}, 1.70 \times 10^{-3}$ and $2.13 \times 10^{-3}$, respectively.

a

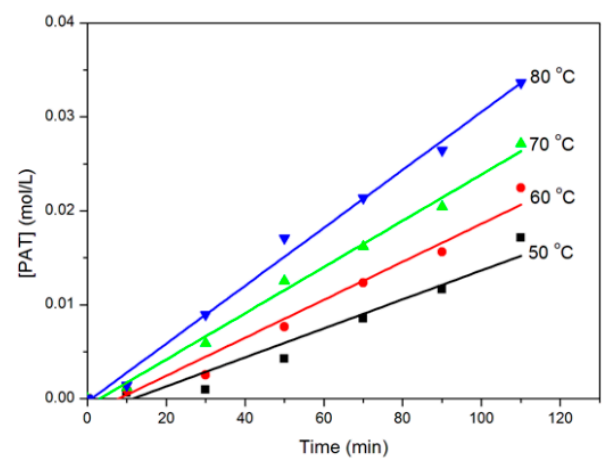

b

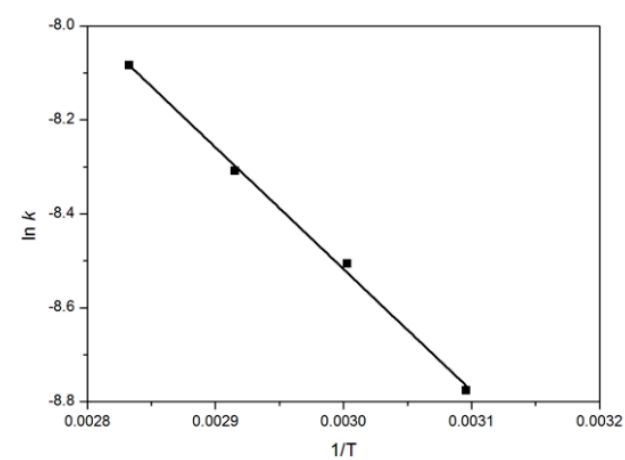

Figure 8. (a) Effect of polymerization temperature on the concentration of PAT at different time intervals; (b) the plot of $\ln k$ versus $1 / T$.

The apparent activation energy $\left(E_{\mathrm{a}}\right)$ of the polymerization of AT was calculated according to the following Arrhenius law:

$$
\ln k=\frac{-E_{\mathrm{a}}}{R T}+\ln A
$$

where $E_{\mathrm{a}}$ is the activation energy, $R$ is the universal gas constant $8.314 \mathrm{~J} \mathrm{~mol}^{-1} \cdot \mathrm{K}^{-1}, T$ is the reaction temperature $(\mathrm{K})$, and $A$ is a constant. The Arrhenius plot of the natural logarithm of $k$ versus the reciprocal of temperature $(1 / T)$ for the polymerization of AT is shown in Figure $8 \mathrm{~b}$. This plot was linear, indicating that the reaction obeyed the Arrhenius law. The activation energy $\left(E_{\mathrm{a}}\right)$ calculated from the slope was $21.57 \pm 0.72 \mathrm{~kJ} / \mathrm{mol}$. This value is much lower than the activation energy of the initiation step of chemical polymerization of pyrrole in water using the oxidant $\mathrm{FeCl}_{3}(79.485 \mathrm{~kJ} / \mathrm{mol})$ [28], and the activation energy of chemical polymerization of poly-o-phenylenediamine in aqueous hydrochloric acid solution using $\mathrm{K}_{2} \mathrm{Cr}_{2} \mathrm{O}_{7}$ as oxidizing agent $(63.658 \mathrm{~kJ} / \mathrm{mol})$ [29], indicating that the polymerization reaction in this study can be readily achieved.

The enthalpy $(\Delta H)$ and entropy $(\Delta S)$ of activation were calculated by the following Eyring equation [29]:

$$
k=\left(\frac{R T}{N h}\right) e^{\Delta S / R} \cdot e^{-\Delta H / R T}
$$

where $N$ is the Avogadro's number, $R$ is the universal gas constant, and $h$ is Planck's constant. The following equation was further obtained by simple mathematical operations:

$$
\ln \left(\frac{k}{T}\right)=\ln \left(\frac{R}{N h}\right)+\frac{\Delta S}{R}+\frac{-\Delta H}{R T}
$$

The relationship between $\ln (\mathrm{k} / \mathrm{T})$ versus $1 / \mathrm{T}$ is shown in Figure 9, giving a linear relationship with $(-\Delta \mathrm{H}) / \mathrm{R}$ as the slope and $(\ln (\mathrm{R} / \mathrm{Nh})+\Delta \mathrm{S} / \mathrm{R})$ as the intercept. The values of $\Delta \mathrm{H}$ and $\Delta \mathrm{S}$ were 
then calculated to be $18.76 \pm 0.73 \mathrm{~kJ} \cdot \mathrm{mol}^{-1}$ and $244.32 \pm 2.16 \mathrm{~J} \cdot \mathrm{mol}^{-1} \cdot \mathrm{K}^{-1}$, respectively. The positive value of $\Delta \mathrm{H}$ indicates the reaction is endothermic [29], while the positive value of the $\Delta S$ means that the entropy of the transition state is more disordered than the entropy of the reactants [28].

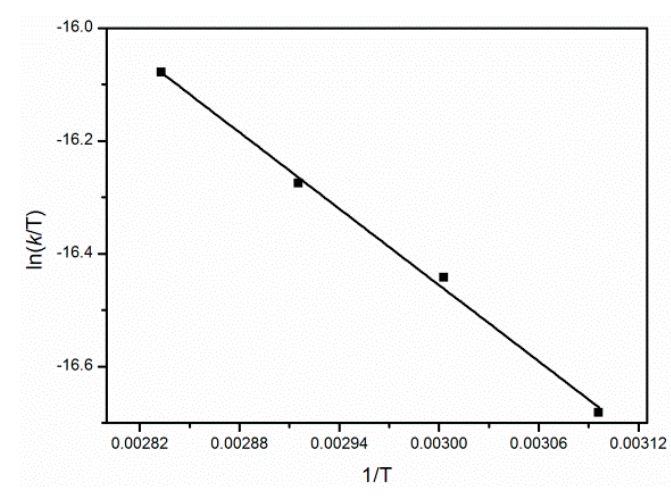

Figure 9. The plot of of In $(k / T)$ versus $1 / T$.

\section{Conclusions}

In this work, the chemical oxidative polymerization of $\mathrm{AT}$ by $\mathrm{CuCl}_{2}$ in aqueous solution was studied systematically. When the polymerization time was $48 \mathrm{~h}$ and the oxidant/monomer molar ratio was 0.2 , a very high yield of PAT $(\sim 81 \%)$ was achieved at $70^{\circ} \mathrm{C}$. In comparison with that prepared using $\mathrm{FeCl}_{3}$ as an oxidant in nitromethane under the same conditions, PAT synthesized with $\mathrm{CuCl}_{2} / \mathrm{H}_{2} \mathrm{O}$ had a higher yield, longer conjugation length and higher molecular weight. The polymer had a granular morphology, which is common for conducting polymers. The thermal stability of PATs increased with decreasing oxidant/monomer molar ratio and the electrical conductivities of PATs could be remarkably improved up to $2.1 \times 10^{-4} \mathrm{~S} / \mathrm{cm}$ upon $\mathrm{I}_{2}$ doping for $24 \mathrm{~h}$.

The chemical oxidative polymerization kinetics of AT in the early stage of the polymerization was studied for the first time. The initial rate of polymerization reaction increases with increasing monomer and oxidant concentrations. The exponents of monomer and oxidant were found to be 1.14 and 0.97 , respectively, and the apparent activation energy was determined to be $21.57 \mathrm{~kJ} / \mathrm{mol}$. This indicates that the polymerization reaction can be readily achieved. Both the enthalpy and entropy of activation were positive, revealing that the reaction is endothermic and the entropy of the transition state is more disordered than the entropy of the reactants.

Supplementary Materials: The following are available online at www.mdpi.com/2073-4360/8/11/407/s1. Figure S1: FT-IR spectra of AT and PAT; Figure S2: PAT with two tautomeric forms and ${ }^{1} \mathrm{H}$ NMR spectra of AT and PAT; Figure S3: UV-vis spectra of AT and PAT synthesized with various oxidant/monomer molar ratio.

Acknowledgments: This work is supported by the National Natural Science Foundation of China (51203090, 51503123, 51673039), the Natural Science Foundation of Shanghai (12ZR1446700), Shanghai Pujiang Program (15PJ1406400, 16PJ1400300), Program of Young Eastern Scholar from Shanghai Institutions of Higher Learning (QD2015014), the Fundamental Research Funds for the Central Universities (16D110618), University of Shanghai for Science and Technology and Hujiang Foundation of China (B14006). Alex Malins is thanked for the critical reading of the manuscript.

Author Contributions: Hua Zou and Lu Wang performed experiments and wrote the paper; Lu Wang and Pengfei Lv analyzed the data; Xia Wang and Yaozu Liao revised the paper.

Conflicts of Interest: The authors declare no conflict of interest.

\section{References}

1. Chen, S.; Lu, B.Y.; Duan, X.M.; Xu, J.K. Systematic study on chemical oxidative and solid-state polymerization of poly(3,4-ethylenedithiathiophene). J. Polym. Sci. Part A 2012, 50, 1967-1978. [CrossRef]

2. Roldan, P.S.; Alcântara, I.L.; Rocha, J.C.; Padilha, C.F.; Padilha, P.M. Determination of copper, iron, nickel and zinc in fuel kerosene by FAAS after adsorption and pre-concentration on 2-aminothiazolemodified silica gel. Eclética Química 2004, 29, 33-40. [CrossRef] 
3. Roldan, P.S.; Alcântara, I.L.; Castro, G.R.; Rocha, J.C.; Padilha, C.F.; Padilha, P.M. Determination of Cu, Ni, and $\mathrm{Zn}$ in fuel ethanol by FAAS after enrichment in column packed with 2-aminothiazolemodified silica gel. Anal. Bioanal. Chem. 2003, 375, 574-577. [CrossRef] [PubMed]

4. Alcântara, I.L.; Roldan, P.S.; Margionte, M.A.L.; Castro, G.R.; Padilha, C.F.; Florentino, A.O.; Padilha, P.M. Determination of $\mathrm{Cu}, \mathrm{Ni}$ and $\mathrm{Pb}$ in aqueous medium by FAAS after preconcentration on 2-aminothiazole modified silica gel. J. Braz. Chem. Soc. 2004, 15, 366-371. [CrossRef]

5. Alcântara, I.L.; Roldan, P.S.; Castro, G.R. Determination of cadmium in river water samples by flame AAS after on-line preconcentration in mini-column packed with 2-aminothiazole-modified silica gel. Anal. Sci. 2004, 27, 1029-1032. [CrossRef]

6. Valtair, M.C.; Araujo, A.B.; Sônia, M.A.; Ariovaldo, O.F.; Valente, J.P.S.; Pedro, M. Enhanced photocatalytic reduction of $\mathrm{Hg}(\mathrm{II})$ in aqueous medium by 2-aminothiazole-modified $\mathrm{TiO}_{2}$ particles. J. Braz. Chem. Soc. 2006, 17, 453-457.

7. Xiong, C.H.; Jia, Q.; Chen, X.Y.; Wang, G.T.; Yao, C.P. Optimization of polyacrylonitrile-2-aminothiazole resin synthesis, characterization, and its adsorption performance and mechanism for removal of $\mathrm{Hg}$ (II) from aqueous solutions. Ind. Eng. Chem. Res. 2013, 52, 4978-4986. [CrossRef]

8. Xiong, C.H.; Zhou, S.G.; Liu, X.Z.; Jia, Q.; Ma, C.N.; Zheng, X.M. 2-Aminothiazole functionalized polystyrene for selective removal of $\mathrm{Au}(\mathrm{III})$ in aqueous solutions. Ind. Eng. Chem. Res. 2014, 53, 2441-2448. [CrossRef]

9. Shan, C.; Ma, Z.Y.; Tong, M.P.; Ni, J.R. Removal of Hg (II) by poly(1-vinylimidazole)-grafted $\mathrm{Fe}_{3} \mathrm{O}_{4} @ \mathrm{SiO}_{2}$ magnetic nanoparticles. Water Res. 2015, 69, 252-260. [CrossRef] [PubMed]

10. Çiftçi, H.; Öktem, Z. Voltammetric determination of $\mathrm{Hg}$ (II) at poly(2-aminothiazole) modified platinum electrode. Fresen. Environ. Bull. 2011, 20, 924-928.

11. Dubrovskii, R.A.; Aksiment'eva, E.A. Anodic synthesis and properties of polyaminothiazole. Russ. J. Electrochem. 2008, 44, 234-237. [CrossRef]

12. Solmaz, R.; Kardaş, G. Electrochemical synthesis and characterization of poly-2-aminothiazole. Prog. Org. Coat. 2009, 64, 81-88. [CrossRef]

13. Solmaz, R. Electrochemical synthesis of poly-2-aminothiazole on mild steel and its corrosion inhibition performance. Prog. Org. Coat. 2011, 70, 122-126. [CrossRef]

14. Solmaz, R.; Şahin, E.A.; Kardaş, G. Electrochemical preparation and characterization of nickel and zinc-modified poly-2-aminothiazole films on mild steel surface and their corrosion inhibition performance. React. Funct. Polym. 2011, 71, 1148-1154. [CrossRef]

15. Çiftçi, H.; Testereci, H.N.; Öktem, Z. Electrochemical polymerization of 2-aminothiazole. Polym. Bull. 2010, 66, 747-760. [CrossRef]

16. Yildirim, M.; Kaya, I. A comparative study of aminothiazole-based polymers synthesized by chemical oxidative polymerization. Synth. Met. 2012, 162, 436-443. [CrossRef]

17. Nabid, M.R.; Bide, Y. Morphological investigation of poly(2-aminothiazole) prepared by rapid initiated polymerization. Adv. Polym. Technol. 2016. [CrossRef]

18. Ciftci, H.; Testereci, H.N.; Öktem, Z. Ring opening polymerization of 2-aminothiazole with iron(III) chloride. Polym. Bull. 2013, 70, 1895-1909. [CrossRef]

19. Biyikoglu, M.; Ciftci, H. Chemical synthesis and characterization of soluble conducting poly(2-aminothiazole). Polym. Bull. 2013, 70, 2843-2856. [CrossRef]

20. Wang, X.; Wang, L.; Zou, H.; Qian, W.; Liao, Y.Z. Simple synthesis of conducting poly(2-aminothiazole) with high molecular weight. Colloid Polym. Sci. 2015, 293, 2027-2034. [CrossRef]

21. Wang, X.; Lv, P.F.; Zou, H.; Li, Y.; Li, X.Y.; Liao, Y.Z. Synthesis of poly(2-aminothiazole) for selective removal of $\mathrm{Hg}(\mathrm{II})$ in aqueous solutions. Ind. Eng. Chem. Res. 2016, 55, 4911-4918. [CrossRef]

22. Tzou, K.; Gregory, R.V. Kinetic study of the chemical polymerization of aniline in aqueous solutions. Synth. Met. 1992, 47, 267-277. [CrossRef]

23. Fu, Y.P.; Elsenbaumer, R.L. Thermochemistry and kinetics of chemical polymerization of aniline determined by solution calorimetry. Chem. Mater. 1994, 6, 671-677. [CrossRef]

24. Gill, M.T.; Chapman, S.E.; DeArmitt, C.L.; Baines, F.L.; Dadswell, C.M.; Stamper, J.G.; Lawless, G.A.; Billingham, N.C.; Armes, S.P. A study of the kinetics of polymerization of aniline using proton NMR spectroscopy. Synth. Met. 1998, 93, 227-233. [CrossRef]

25. Chakraborty, M.; Mukherjee, D.C.; Mandal, B.M. Dispersion polymerization of aniline in different media: A UV-visible spectroscopic and kinetic study. Langmuir 2000, 16, 2482-2488. [CrossRef] 
26. Minami, H.; Okubo, M.; Murakami, K.; Hirano, S. Kinetics of chemical oxidative dispersion polymerization of 3,5-xylidine in aqueous medium using a PH stat method. J. Polym. Sci. Part A 2000, 38, 4238-4246. [CrossRef]

27. Sivakumar, C.; Gopalan, A.; Vasudevan, T.; Wen, T.C. Kinetics of polymerization of N-methyl aniline using UV-VIS spectroscopy. Synth. Met. 2002, 126, 123-135. [CrossRef]

28. Tan, Y.; Ghandi, K. Kinetics and mechanism of pyrrole chemical polymerization. Synth. Met. 2013, 175, 183-191. [CrossRef]

29. Sayyah, S.M.; Khaliel, A.B.; Aboud, A.A.; Mohamed, S.M. Chemical polymerization kinetics of poly-o-phenylenediamine and characterization of the obtained polymer in aqueous hydrochloric acid solution using $\mathrm{K}_{2} \mathrm{Cr}_{2} \mathrm{O}_{7}$ as oxidizing agent. Int. J. Polym. Sci. 2014. [CrossRef]

30. Stejskal, J.; Sapurina, I.; Trchova, M. Polyaniline nanostructures and the role of aniline oligomers in their formation. Prog. Polym. Sci. 2010, 35, 1420-1481. [CrossRef]

31. Kopecká, J.; Kopecký, D.; Vrňata, M.; Fitl, P.; Stejskal, J.; Trchová, M.; Bober, P.; Morávková, Z.; Prokeš, J.; Sapurina, I. Polypyrrole nanotubes: Mechanism of formation. RSC Adv. 2014, 4, 1551-1558. [CrossRef]

32. Leonavicius, K.; Ramanaviciene, A.; Ramanavicius, A. Polymerization model for hydrogen peroxide initiated synthesis of polypyrrole nanoparticles. Langmuir 2011, 27, 10970-10976. [CrossRef] [PubMed]

(C) 2016 by the authors; licensee MDPI, Basel, Switzerland. This article is an open access article distributed under the terms and conditions of the Creative Commons Attribution (CC-BY) license (http://creativecommons.org/licenses/by/4.0/). 